\title{
Clinical Factors Influencing Quality of Life in Anorexia Nervosa Patients
}

\author{
Chikako Kane ${ }^{1 *}$, Masahito Tomotake², Sayo Hamatani' ${ }^{3}$ \\ Shinichi Chiba' ${ }^{2}$, Tetsuro Ohmori4
}

${ }^{1}$ Graduate School of Health Sciences, Tokushima University, Tokushima, Japan

${ }^{2}$ Department of Mental Health, Institute of Biomedical Sciences, Tokushima University Graduate School, Tokushima, Japan

${ }^{3}$ Research Center for Child Mental Development, Chiba University, Chiba, Japan

${ }^{4}$ Department of Psychiatry, Institute of Biomedical Sciences, Tokushima University Graduate School, Tokushima, Japan

Email: *t.kane@kangotoku.jp

How to cite this paper: Kane, C., Tomotake, M., Hamatani, S., Chiba, S. and Ohmori, T. (2018) Clinical Factors Influencing Quality of Life in Anorexia Nervosa $\mathrm{Pa}$ tients. Open Journal of Psychiatry, 8, 50-60. https://doi.org/10.4236/ojpsych.2018.81004

Received: November 15, 2017

Accepted: December 24, 2017

Published: December 27, 2017

Copyright (C) 2018 by authors and Scientific Research Publishing Inc. This work is licensed under the Creative Commons Attribution International License (CC BY 4.0).

http://creativecommons.org/licenses/by/4.0/

(c) (i) Open Access

\begin{abstract}
Objective: The purpose of this study was to elucidate clinical factors influencing quality of life (QOL) in anorexia nervosa (AN) patients. Methods: Twenty female patients with AN (median age $=30.0$ years, quartile deviation $=6.8$ ) and forty female healthy controls $(\mathrm{HC})$ (median age $=30.0$ years, quartile deviation $=8.6$ ) participated in the study. QOL was assessed with the 36-Item Short Form Health Survey (SF-36) and social support was evaluated using the Multidimensional Scale of Perceived Social Support (MSPSS). Clinical symptoms were evaluated with the Structured Interview Guide for the Hamilton Depression Rating Scale (SIGH-D) and the Eating Disorder Inventory-2 (EDI-2). Results: Scores of the SF-36 Mental Component Summary (MCS) ( $U=124.0, P$ $<0.0001)$ and Role/Social Component Summary (RCS) $(U=223.0, P=0.006)$ and scores of total $(U=108.0, P<0.0001)$ and subscales of the MSPSS were lower in AN group than HC group, and the SIGH-D score was higher ( $U=46.0$, $P<0.0001)$ in AN group than HC group. Scores of the SIGH-D $(\rho=-0.565, P$ $<0.05)$ and subscales of the EDI-2 Interoceptive Confusion $(\rho=-0.556, P<$ $0.05)$, Interpersonal Difficulty $(\rho=-0.581, P<0.05)$ and Negative Self-image ( $\rho=-0.617, P<0.05)$ were negatively correlated to MCS, and score of Interoceptive Confusion subscale showed a negative correlation to RCS ( $\rho=-0.672$, $P<0.05)$. Moreover, stepwise regression analysis showed that the SIGH-D score was an independent predictor of MCS and Interoceptive Confusion score predicted RCS. Conclusion: These results suggest that among a variety of clinical symptoms and psychopathologies, depressive symptoms, poor emotional awareness and impaired sense of control are the most important influencing factors on AN patients' QOL.
\end{abstract}




\section{Keywords}

Anorexia Nervosa, Quality of Life, Influencing Factor, Depression, Interoceptive Confusion

\section{Introduction}

Among eating disorders, anorexia nervosa (AN) has been proving a difficult condition, with many patients remaining ill for many years, and patients with AN suffer from physical, psychological and social problems as a result of the disease [1] [2]. Preferably, treatment goal should be full symptom remission, but it is often difficult to achieve this goal in the treatment of AN. Therefore, in addition to symptom reduction, therapists have got to pay attention to more global indicators such as subjective well-being and quality of life (QOL) to know patients' improvement [3].

Over the past decades, QOL has become crucial as an indicator of recovery of patients with AN [3], and their QOL has been investigated from differing points of view [1]. Researchers have reported that AN patients showed lower QOL than healthy people [4] [5] [6] [7] and those patients who had partial eating disorder symptoms or psychiatric comorbidity had low QOL [8]-[15]. Bamford et al. [2] [11] reported that severity of eating disorder and body mass index (BMI) were predictors of low QOL, and from the survey on social support, it was revealed that AN patients often reported dissatisfaction with family environment and low support by family members or friends which was associated with their low QOL [16].

Since the treatment of AN generally takes a long term and patients suffer from low QOL during the treatment period [7], it is of significance that therapists pay attention to their QOL and make as much effort as possible to improve it. Although researchers have reported several factors related to AN patients' poor QOL, as far as we know, which clinical factors strongly influence their QOL and how much impact they have on it remain unclear. Therefore, we conducted this study to elucidate clinical factors potently associated with their poor QOL.

\section{Methods}

\subsection{Subjects}

Clinical data were collected at the Department of Psychiatry, Tokushima University Hospital from 1 March 2016 to 30 June 2017. Subjects consisted of twenty female outpatients having a Diagnostic and Statistical Manual of Mental Disorders-5 [17] diagnosis of AN and forty female healthy controls (HC). Patients were excluded if they presented with any organic central nervous system disorder, severe somatic disorder, substance dependence, epilepsy or mental retardation. Of twenty-three outpatients to whom we explained the research, twenty (87.0\%) agreed to participate in this study. As for HC, subjects were excluded if they had a history of any psychiatric illness or if their BMI was not within normal range 
(18.5 - 24.9) [18]. We recruited HC from students and staffs at Tokushima University.

All subjects were native Japanese speakers and gave us written consent to participate in this study.

\subsection{Measures}

Subjects were examined by experienced clinical researchers using the following measures.

1) The Structured Interview Guide for the Hamilton Depression Rating Scale (SIGH-D)

Severity of depression was evaluated with Japanese version of the SIGH-D [19] [20]. The SIGH-D was developed to standardize the manner of administration of the Hamilton Depression Rating Scale. The Japanese version has a good reliability and validity [21]. In the present study, we used the 21-item version and in the scale, higher score indicates more severe depression level.

2) Eating Disorder Inventory-2 (EDI-2)

Japanese version of the EDI-2 [22] [23] is a self-report questionnaire. The EDI-2 was designed to provide a comprehensive assessment of the behavioral and psychological characteristics of eating disorder patients. From the result of factor analysis, it is revealed that the Japanese version consists of nine factors [22]. The nine factors are as follows: Drive for Thinness, Body Dissatisfaction, Bulimia, Interoceptive Confusion, Interpersonal Difficulty, Negative Self-image, Compulsion for Control, Impulse Regulation and Maturity Fears. The scoring method was based on Garner's rationale [23] and higher score of this scale indicates severer AN symptomatology. The reliability and validity of the Japanese version is already confirmed [22].

3) Multidimensional Scale of Perceived Social Support (MSPSS)

To assess perceived social support, Japanese version of the MSPSS [24] [25] [26] was administered to the subjects. The MSPSS consists of twelve self-report items and has three subscales that are Family, Significant Other and Friends. In this scale, higher score means higher level of social support. The reliability and validity of the Japanese version is already confirmed [24].

4) 36-Item Short Form Health Survey (SF-36)

Japanese version of the SF-36 was administered to the subjects in order to evaluate their health-related QOL [27] [28] [29]. The SF-36 is a self-report questionnaire to assess elements of physical functioning, general health perception, and vitality, role emotional and mental health. In the present study, we used the three-component model that is composed of Physical Component Summary (PCS), Mental Component Summary (MCS) and Role/Social Component Summary (RCS) [30]. Higher score of this scale indicates better QOL. It is reported that the Japanese version has a good reliability and validity [27] [28] [29].

\subsection{Statistical Analysis}

Data analysis was performed using the predictive Analytics Software Statistics 22 
software (2009; SPSS Japan Institute). As several data showed non-normal distribution, we chose the Mann-Whitney $U$ test to compare age, length of education, BMI, the SIGH-D score, the MSPSS score and the SF-36 score between AN and $\mathrm{HC}$ groups. And $\mathrm{r}(\mathrm{Z} / \sqrt{ } \mathrm{N})$ was calculated to provide effect size [31]. Then for AN group, Spearman rank correlation coefficients were calculated to explore the relation between the SF-36 and other clinical variables. Statistical significance was adjusted for multiple comparisons (False Discovery Rate correction) [32]. After that, choosing the SF-36 components as dependent variables and the clinical variables that showed significant correlations with each component of the SF-36 as independent variables, forward stepwise regression analyses were performed to explore which clinical variables would predict each dependent variable.

\subsection{Ethical Considerations}

This study was approved by the Clinical Research Ethics Committee of Tokushima University Hospital.

\section{Results}

The demographic and clinical characteristics of the AN and $\mathrm{HC}$ groups are shown in Table 1 . There was no significant difference in age and length of education between the two groups. AN group showed significant lower BMI ( $U=77.0, P<$ $0.0001, r=-0.65)$ and higher SIGH-D score $(U=46.0, P<0.0001, r=-0.81)$ than $\mathrm{HC}$ group. AN group also showed significant lower scores in the MSPSS total $(U=108.0, P<0.0001, r=-0.59$ ), Significant Other Subscale ( $U=142.0, P$ $<0.0001, r=-0.53)$, Family Subscale $(U=155.5, P<0.001, r=-0.50)$ and Friends Subscale $(U=128.5, P<0.0001, r=-0.55)$ than HC group. As for SF-36, there was no significant difference in PCS score between AN and HC groups, but AN group showed significantly lower scores for MCS ( $U=124.0, P<0.0001, r=-0.56)$ and RCS ( $U=223.0, P<0.01, r=-0.36$ ) than HC group.

Correlations between the SF-36 and other clinical variables in AN group are shown in Table 2. The SIGH-D score $(\rho=-0.565, P<0.05)$ and scores of Interoceptive Confusion $(\rho=-0.556, P<0.05)$, Interpersonal Difficulty $(\rho=-0.581$, $P<0.05)$ and Negative Self-image $(\rho=-0.617, P<0.05)$ of the EDI-2 showed significant correlations with MCS. The EDI-2 Interoceptive Confusion score showed a significant correlation with RCS $(\rho=-0.672, P<0.05)$. On the other hand, there was no significant correlation between PCS and other clinical variables.

Table 3 shows the results of stepwise regression analysis. MCS score was significantly predicted by the SIGH-D score and RCS score by the EDI-2 Interoceptive Confusion score.

\section{Discussion}

$\mathrm{AN}$ is renowned as being difficult to treat and chronic course is common [33] 
[34]. AN patients show a variety of clinical symptoms such as depression and extremely low BMI, and they suffer from those symptoms and other psychological problems including lack of confidence, low self-esteem and less satisfaction of life [16] [35] [36] [37] [38]. Therapists need to assess their condition from comprehensive viewpoints in order to give them better care and treatment. Therefore, evaluation of AN patients' QOL has become more important [1]. Since it is of significance for therapists to make as much effort as possible to improve patients' poor QOL, investigating clinical factors influencing their QOL is considered to be crucial.

Table 1. Demographic and clinical characteristics of AN and HC groups.

\begin{tabular}{|c|c|c|c|c|c|c|}
\hline & & AN group $(n=20)$ & HC group $(n=40)$ & Statistics & $P$-value & Effect size \\
\hline Age (years) & & $30.0(6.8)$ & $30.0(8.6)$ & $\mathrm{U}=395.5$ & 0.944 & -0.01 \\
\hline Length of education (years) & & $14.3(2.4)$ & $15.0(0.9)$ & $\mathrm{U}=333.0$ & 0.279 & -0.14 \\
\hline \multirow[t]{4}{*}{ Social state $(\mathrm{n})$} & Full Time & 4 & 30 & & & \\
\hline & Part Time & 2 & - & & & \\
\hline & No Employment & 12 & - & & & \\
\hline & Student & 2 & 10 & & & \\
\hline Age of onset (years) & & $19.0(4.3)$ & - & - & - & - \\
\hline Duration of illness (years) & & $7.0(2.5)$ & - & - & - & - \\
\hline BMI $\left(\mathrm{kg} / \mathrm{m}^{2}\right)$ & & $15.3(2.0)$ & $20.8(1.4)$ & $\mathrm{U}=77.0^{\star * *}$ & $<0.0001$ & -0.65 \\
\hline SIGH-D & & $13.5(5.4)$ & $0.0(0.0)$ & $\mathrm{U}=46.0^{* * *}$ & $<0.0001$ & -0.81 \\
\hline \multirow[t]{9}{*}{ EDI-2 } & Drive for Thinness & $11.0(6.4)$ & - & - & - & - \\
\hline & Body Dissatisfaction & $12.0(7.6)$ & - & - & - & - \\
\hline & Bulimia & $7.5(5.3)$ & - & - & - & - \\
\hline & Interoceptive Confusion & $9.5(6.3)$ & - & - & - & - \\
\hline & Interprersonal Difficulty & $8.5(4.5)$ & - & - & - & - \\
\hline & Negative Self-Image & $8.0(2.9)$ & - & - & - & - \\
\hline & Compulsion for Control & $4.0(2.9)$ & - & - & - & - \\
\hline & Impulse Regulation & $4.0(2.8)$ & - & - & - & - \\
\hline & Maturity Fears & $1.5(2.4)$ & - & - & - & - \\
\hline \multirow[t]{4}{*}{ MSPSS } & Family & $5.0(0.9)$ & $6.0(0.7)$ & $\mathrm{U}=155.5^{\star \star}$ & $<0.001$ & -0.50 \\
\hline & Significant Other & $4.5(1.2)$ & $6.5(0.6)$ & $\mathrm{U}=142.0^{* * *}$ & $<0.0001$ & -0.53 \\
\hline & Friends & $3.3(1.5)$ & $6.0(0.8)$ & $\mathrm{U}=128.5^{\star * *}$ & $<0.0001$ & -0.55 \\
\hline & Total & $4.4(1.2)$ & $6.2(0.5)$ & $\mathrm{U}=108.0^{* * *}$ & $<0.0001$ & -0.59 \\
\hline \multirow[t]{3}{*}{ SF-36 } & Physical Component Summary & $54.1(5.7)$ & $56.9(3.8)$ & $\mathrm{U}=332.0$ & 0.286 & -0.16 \\
\hline & Mental Component Summary & $37.9(8.2)$ & $53.0(5.6)$ & $\mathrm{U}=124.0^{* * *}$ & $<0.0001$ & -0.56 \\
\hline & Role/Social Component Summary & $35.4(15.8)$ & $50.3(5.2)$ & $\mathrm{U}=223.0^{*}$ & 0.006 & -0.36 \\
\hline
\end{tabular}

Note: Results are median with QD, ${ }^{\star} P<0.01,{ }^{* *} P<0.001,{ }^{* *} P<0.0001$, Mann-Whitney U-test. Abbreviations: QD, quartile deviation; AN, anorexia nervosa; HC, healthy control; BMI, Body mass index; SIGH-D, Structured Interview Gide for the Hamilton Depression Rating Scale; EDI-2, Eating disorder Inventory-2; MSPSS, Multidimensional Scale of Perceived Social Support; SF-36, 36-Item short Form Health Survey; PCS, Physical Component Summary; MCS, Mental Component Summary; RCS, Role/social Component Summary. 
Table 2. Correlations between SF-36 and clinical variables.

\begin{tabular}{|c|c|c|c|c|}
\hline & & \multicolumn{3}{|c|}{ SF-36 } \\
\hline & & PCS & MCS & RCS \\
\hline Length of education & & 0.294 & -0.022 & 0.086 \\
\hline Age of onset & & 0.016 & -0.429 & 0.037 \\
\hline Duration of illness & & -0.242 & 0.153 & -0.024 \\
\hline BMI & & 0.201 & 0.147 & -0.163 \\
\hline SIGH-D & & -0.221 & $-0.565^{\star}$ & -0.342 \\
\hline \multirow[t]{9}{*}{ EDI-2 } & Drive for Thinness & 0.093 & -0.452 & -0.023 \\
\hline & Body Dissatisfaction & 0.135 & -0.361 & -0.050 \\
\hline & Bulimia & -0.166 & -0.516 & -0.172 \\
\hline & Interoceptive Confusion & -0.077 & $-0.556^{*}$ & $-0.672^{*}$ \\
\hline & Interpersonal Difficulty & -0.210 & $-0.581^{\star}$ & -0.429 \\
\hline & Negative Self-Image & -0.017 & $-0.617^{*}$ & -0.420 \\
\hline & Compulsion for Control & 0.046 & -0.411 & -0.390 \\
\hline & Impulse Regulation & -0.100 & -0.189 & -0.519 \\
\hline & Maturity Fears & 0.123 & -0.531 & -0.194 \\
\hline \multirow[t]{4}{*}{ MSPSS } & Family & 0.016 & 0.469 & 0.203 \\
\hline & Significant Other & 0.271 & 0.414 & 0.314 \\
\hline & Friends & 0.473 & 0.297 & 0.380 \\
\hline & Total & 0.289 & 0.403 & 0.368 \\
\hline
\end{tabular}

Notes: ${ }^{\star} P<0.05$, Spearman rank correlation (False Discovery Rate correction). Abbreviations: BMI, Body mass index; SIGH-D, Structured Interview Gide for the Hamilton Depression Rating Scale; EDI-2, Eating disorder Inventory-2; MSPSS, Multidimensional Scale of Perceived Social Support; PCS, Physical Component Summary; MCS, Mental Component Summary; RCS, Role/social Component Summary.

Table 3. Results of stepwise regression analyses on SF-36.

\begin{tabular}{cccc}
\hline Dependent Variable & Independent Variable & Adjusted $\mathrm{R}^{2}$ & $\beta$ \\
\hline MCS & SIGH-D & $0.425^{* *}$ & $-0.675^{* *}$ \\
RCS & EDI-2 Interoceptive Confusion & $0.431^{* * *}$ & $-0.679^{* *}$ \\
\hline
\end{tabular}

Notes: ${ }^{*} P<0.01,{ }^{* * *} P<0.001$. Abbreviations: MCS, Mental Component Summary; RCS, Role/social Component Summary; SIGH-D, Structured Interview Gide for the Hamilton Depression Rating Scale; EDI-2, Eating disorder Inventory-2.

In the present study, as expected, there are significant differences in certain aspects of QOL as well as in depression level and perceived social support between AN and HC groups. Previous studies reported similar findings that AN patients had lower QOL and more severe depression level than HC [6] [7] [9] [12] [15] [16], and it was also reported that AN patients had less satisfaction of family relationships and support [16]. Therefore, our findings generally support the previous results. However, in the present study, there was no significant difference in PCS of the SF-36 between AN and HC groups. This finding is similar 
to the finding that Hamatani et al. [39] reported. Mitchison et al. [12] discovered that people with a history of AN showed no significant difference in PCS compared to HC group in spite of the fact that AN group showed significantly lower score in MCS. Since it is known that AN patients tend to ignore their physical condition as if they don't have any physical problems [40], this finding may reflect their attitudes towards physical health or condition.

In addition to those findings, we could newly discover that depression and eating psychopathology would predict certain aspects of QOL. So far, several researchers have reported the relations between AN patients' QOL and several clinical factors such as depression [7] [9] [15], psychopathology [3] [41] and low BMI [2] [11] [15]. As for psychopathology of AN, Abraham et al. [41] reported that QOL was negatively correlated to eating disorder behavior and attitude. Abbate-Daga et al. [3] investigated AN patients' health-related QOL and reported that their QOL correlated with eating psychopathology such as body dissatisfaction, interoceptive awareness, ineffectiveness, impulsivity and social insecurity. As for BMI, Bamford et al. [11] pointed out that BMI was a predictor of low QOL. On the other hand, Abbate-Daga et al. [2] reported that AN patients' QOL was not associated with BMI. In the current study, from the results of stepwise regression analysis, it is revealed that the SF-36 MCS is negatively related to depression level and RCS to Interoceptive Confusion score. However, we found no significant correlation between the SF-36 and other clinical variables including BMI, age of onset, duration of illness and perceived social support.

Our results clearly show that eating disorder psychopathology of interoceptive confusion has much more negative impact on AN patients' QOL than other eating disorder psychopathologies. Interoceptive Confusion subscale consists of eight items [22]. Some examples are as follows; "When I am upset, I don't know if I am sad, scared or mad", "I get confused about what feeling I have", "I don't know what's going on inside me", "I have feelings I can't name", "I worry that my feelings will get out of control", and "I get bad thoughts in my head that I can't get rid of". These items are asking about how much patients are aware of their own emotion and to what extent they have impaired sense of control [22]. Hamatani et al. [42] reported that AN patients were not good at monitoring and evaluating their own cognitive activities and the characteristic was associated with low QOL. Our results show that poor emotional awareness and low sense of control are also related to low QOL. We infer that those psychopathologies would be more likely to make AN patients less satisfied and confident in social or personal context, which may lead to low QOL.

Considering these findings, we could conclude that depression, poor emotional awareness and low sense of control are significant predictors of AN patients' low QOL. Treating those factors well may lead to better QOL. However, as De Houwer [43] pointed out, self-report questionnaire to AN patients may not be able to capture their negative thoughts, beliefs or behaviors because they are often unaware of those. Therefore, careful interpretation may be required. 


\section{Limitations}

This study has some limitations. First, since this study was a cross-sectional study, we can only guess at the developmental causality. Second, as the sample size was small, further study with a larger sample size would be required to confirm the results. Third, since the SF-36 is a self-report questionnaire, AN patients' responses might have been influenced by their denial of negative aspects of QOL [43].

\section{Conclusion}

The results suggest that not only depressive symptoms but also poor emotional awareness and impaired sense of control are much more important as influencing factors on AN patients' QOL than other clinical factors.

\section{Acknowledgements}

The authors would like to thank all subjects for participating in this study.

\section{Disclosure}

The authors report no conflicts of interest in this work.

\section{References}

[1] Sy, R., Ponton, K., De Marco, P., Pi, S. and Ishak, W.W. (2013) Quality of Life in Anorexia Nervosa: A Review of the Literature. Eating Disorders, 21, 206-222. https://doi.org/10.1080/10640266.2013.779176

[2] Bamford, B., Barras, C., Sly, R., Stiles-Shields, C., Touyz, S., Le Grange, D., Hay, P., Crosby, R. and Lacey, H. (2015) Eating Disorder Symptoms and Quality of Life: Where Should Clinicians Place Their Focus in Severe and Enduring Anorexia Nervosa? International Journal of Eating Disorders, 48, 133-138. https://doi.org/10.1002/eat.22327

[3] Abbate-Daga, G., Facchini, F., Marzola, E., Delsedime, N., Giovannone, C., Amianto, F. and Fassino, S.E. (2014) Health-Related Quality of Life in Adult Inpatients Affected by Anorexia Nervosa. European Eating Disorders Review, 22, 285-291. https://doi.org/10.1002/erv.2302

[4] De la Rie, S.M., Noordenbos, G. and van Furth, E.F. (2005) Quality of Life and Eating Disorders. Quality of Life Research, 14, 1511-1522. https://doi.org/10.1007/s11136-005-0585-0

[5] Mond, J.M., Hay, P.J., Rodgers, B., Owen, C. and Beumont, P.J. (2005) Assessing Quality of Life in Eating Disorder Patients. Quality of Life Research, 14, 171-178. https://doi.org/10.1007/s11136-004-2657-y

[6] Muñoz, P., Quintana, J.M., Las Hayas, C., Aguirre, U., Padierna, A. and González-Torres, M.A. (2009) Assessment of the Impact of Eating Disorders on Quality of Life Using the Disease-Specific, Health-Related Quality of Life for Eating Disorders (HeRQoLED) Questionnaire. Quality of Life Research, 18, 1137-1146. https://doi.org/10.1007/s11136-009-9542-7

[7] Pohjolainen, V., Koponen, S., Räsänen, P., Roine, R.P., Sintonen, H. and Karlsson, H. (2016) Long-Term Health-Related Quality of Life in Eating Disorders. Quality of Life Research, 25, 2341-2346. https://doi.org/10.1007/s11136-016-1250-5

[8] González-Pinto, A., Inmaculada, F., Cristina, R., de Corres Blanca, F., Sonsoles, E., 
Fernando, R. and Purificacion, L. (2004) Purging Behaviors and Comorbidity as Predictive Factors of Quality of Life in Anorexia Nervosa. International Journal of Eating Disorders, 36, 445-450. https://doi.org/10.1002/eat.20058

[9] Doll, H.A., Petersen, S.E. and Stewart-Brown, S.L. (2005) Eating Disorders and Emotional and Physical Well-Being: Associations between Student Self-Reports of Eating Disorders and Quality of Life as Measured by the SF-36. Quality of Life Research, 14, 705-717. https://doi.org/10.1007/s11136-004-0792-0

[10] Padierna, A., Quintana, J.M., Arostegui, I., Gonzalez, N. and Horcajo, M.J. (2002) Changes in Health Related Quality of Life among Patients Treated for Eating Disorders. Quality of Life Research, 11, 545-552. https://doi.org/10.1023/A:1016324527729

[11] Bamford, B. and Sly, R. (2010) Exploring Quality of Life in the Eating Disorders. European Eating Disorders Review, 18, 147-153. https://doi.org/10.1002/erv.975

[12] Mitchison, D., Hay, P., Mond, J. and Slewa-Younan, S. (2013) Self-Reported History of Anorexia Nervosa and Current Quality of Life: Findings from a Community-Based Study. Quality of Life Research, 22, 273-281. https://doi.org/10.1007/s11136-012-0157-Z

[13] DeJong, H., Oldershaw, A., Sternheim, L., Samarawickrema, N., Kenyon, M.D., Broadbent, H., Lavender, A., Startup, H., Treasure, J. and Schmidt, U. (2013) Quality of Life in Anorexia Nervosa, Bulimia Nervosa and Eating Disorder Not-Otherwise-Specified. Journal of Eating Disorders, 1, 43. https://doi.org/10.1186/2050-2974-1-43

[14] Ackard, D.M., Richter, S., Egan, A., Engel, S. and Cronemeyer, C.L. (2014) The Meaning of (Quality of) Life in Patients with Eating Disorders: A Comparison of Generic and Disease-Specific Measures across Diagnosis and Outcome. International Journal of Eating Disorders, 47, 259-267. https://doi.org/10.1002/eat.22193

[15] Weigel, A., König, H.H., Gumz, A., Löwe, B. and Brettschneider, C. (2016) Correlates of Health Related Quality of Life in Anorexia Nervosa. International Journal of Eating Disorders, 49, 630-634. https://doi.org/10.1002/eat.22512

[16] Pollack, L.O., McCune, A.M., Mandal, K. and Lundgren, J.D. (2015) Quantitative and Qualitative Analysis of the Quality of Life of Individuals with Eating Disorders. The Primary Care Companion for CNS Disorders, 17.

[17] American Psychiatric Association (2013) Diagnostic and Statistical Manual of Mental Disorders. 5th Edition, American Psychiatric Association, Washington DC.

[18] World Health Organization Expert Committee on Physical Status, the Use and Interpretation of Anthropometry, Report of WHO Expert Committee (1995) WHO Technical Report Series 854. World Health Organization, Geneva.

[19] Williams, J.B. (1998) A Structure Interview Guide for the Hamilton Depression Rating Scale. Archives of General Psychiatry, 45, 742-747. https://doi.org/10.1001/archpsyc.1988.01800320058007

[20] Nakane, Y. and Williams, J.B. (2003) Japanese Version of Structured Interview Guide for the Hamilton Depression Rating Scale (SIGH-D). Japanese Journal of Clinical Pharmacology, 6, 1353-1368. (In Japanese)

[21] Narita, T., Kim, T., Nakae, Y. and Ozaki, N. (2003) Reliability and Validity of Structured Interview Guide for the Hamilton Depression Rating Scale (SIGH-D). Japanese Journal of Clinical Pharmacology, 6, 72-82. (In Japanese)

[22] Shimura, M., Horie, H., Kumano, H., Sakano, Y. and Suematsu, H. (2003) Reliability and Validity of a Japanese Version of the Eating Disorder Inventory. Psychological Reports, 92, 131-140. https://doi.org/10.2466/pr0.2003.92.1.131 
[23] Garner, D.M. (1991) Eating Disorder Inventry-2. Professional Manual. Psychological Assessment Resources Inc., Odessa.

[24] Iwasa, H., Gondo, Y., Masui, Y., Inagaki, H., Kawaai, C., Otsuka, R., Ogawa, M., Takayama, M., Imuta, H. and Suzuki, T. (2007) Reliability and Validity of the Japanese Version of the Multidimensional Scale of Perceived Social Support among Middle-Aged and Elderly. Journal of Health and Welfare Statistics, 54, 26-33. (In Japanese)

[25] Zimet, G.D., Powell, S.S., Farley, G.K., Werkman, S. and Berkoff, K.A. (1990) Psychometric Characteristics of the Multidimensional Scale of Perceived Social Support. Journal of Personality Assessment, 55, 610-617.

https://doi.org/10.1080/00223891.1990.9674095

[26] Zimet, G.D., Dahlem, N.W., Zimet, S.G. and Farley, G.K. (1988) The Multidemensional Scale of Perceived Social Support. Journal of Personality Assessment, 52, 30-41. https://doi.org/10.1207/s15327752jpa5201_2

[27] Fukuhara, S., Bito, S., Green, J., Hsiao, A. and Kurokawa, K. (1998) Translation, Adaptation, and Validation of the SF-36 Health Survey for Use in Japan. Journal of Clinical Epidemiology, 51, 1037-1044. https://doi.org/10.1016/S0895-4356(98)00095-X

[28] Fukuhara, S., Ware, J.E., Kosinski, M., Wada, S. and Gandek, B. (1998) Psychometric and Clinical Tests of Validity of the Japanese SF-36 Health Survey. Journal of Clinical Epidemiology, 51, 1045-1053. https://doi.org/10.1016/S0895-4356(98)00096-1

[29] Fukuhara, S. and Suzukamo, Y. (2015) Manual of SF-36v2 Japanese Version. iHope International Inc., Kyoto. (In Japanese)

[30] Suzukamo, Y., Fukuhara, S., Green, J., Kosinski, M., Gandek, B. and Ware, J.E. (2011) Validation Testing of a Three-Component Model of Short Form-36 Scores. Journal of Clinical Epidemiology, 64, 301-308. https://doi.org/10.1016/j.jclinepi.2010.04.017

[31] Field, A. (2005) Discovering Statistics using SPSS. 2nd Edition, SAGE Publications, London.

[32] Matsuda, S. (2008) Introduction of FDR and Comparisons of Multiple Testing Procedures That Control It. Japan Journal Biomet, 29, 125-139. (In Japanese) https://doi.org/10.5691/jib.29.125

[33] Herpertz-Dahlmann, B., Müller, B., Herpertz, S., Heussen, N., Hebebrand, J. and Remschmidt, H. (2001) Prospective 10-Year Follow-Up in Adolescent Anorexia Nervosa-Course, Outcome, Psychiatric Comorbidity, and Psychosocial Adaptation. Journal of Child Psychology and Psychiatry, 42, 603-612. https://doi.org/10.1111/1469-7610.00756

[34] Steinhausen, H.C. (2002) The Outcome of Anorexia Nervosa in the 20th Century. The American Journal of Psychiatry, 159, 1284-1293. https://doi.org/10.1176/appi.ajp.159.8.1284

[35] Stice, E. and Shaw, H.E. (2002) Role of Body Dissatisfaction in the Onset and Maintenance of Eating Pathology: A Synthesis of Research Findings. Journal of Psychosomatic Research, 53, 985-993. https://doi.org/10.1016/S0022-3999(02)00488-9

[36] Pollice, C., Kaye, W.H., Greeno, C.G. and Weltzin, T.E. (1997) Relationship of Depression, Anxiety, and Obsessionality to State of Illness in Anorexia Nervosa. International Journal of Eating Disorders, 21, 367-376. https://doi.org/10.1002/(SICI)1098-108X(1997)21:4<367::AID-EAT10>3.0.CO;2-W

[37] Fox, A.P. and Leung, N. (2009) Existential Well-Being in Younger and Older People 
with Anorexia Nervosa-A Preliminary Investigation. European Eating Disorders Review, 17, 24-30. https://doi.org/10.1002/erv.895

[38] Carter, J.C., Bewell, C. and Devins, G.M. (2008) Illness Intrusiveness in Anorexia Nervosa. Journal of Psychosomatic Research, 64, 519-526. https://doi.org/10.1016/j.jpsychores.2008.01.001

[39] Hamatani, S., Tomotake, M., Takeda, T., Kameoka, N., Kawabata, M., Kubo, H., Tada, Y., Tomioka, Y., Watanabe, S., Inoshita, M., Kinoshita, M., Ohta, M. and Ohmori, T. (2017) Influence of Cognitive Function on Quality of Life in Anorexia Nervosa Patients. Psychiatry and Clinical Neurosciences, 71, 328-335. https://doi.org/10.1111/pcn.12491

[40] Bruch, H. (1982) Anorexia Nervosa: Therapy and Theory. The American Journal of Psychiatry, 139, 1531-1538. https://doi.org/10.1176/ajp.139.12.1531

[41] Abraham, S.F., Brown, T., Boyd, C., Luscombe, G. and Russell, J. (2006) Quality of Life: Eating Disorders. Australian \& New Zealand Journal of Psychiatry, 40, 150-155. https://doi.org/10.1080/j.1440-1614.2006.01762.x

[42] Hamatani, S., Tomotake, M., Takeda, T., Kameoka, N., Kawabata, M., Kubo, H., Tada, Y., Tomioka, Y., Watanabe, S. and Ohmori, T. (2016) Impaired Social Cognition in Anorexia Nervosa Patients. Neuropsychiatric Disease and Treatment, 12, 2527-2531. https://doi.org/10.2147/NDT.S116521

[43] De Houwer, J. (2002) The Implicit Association Test as a Tool for Studying Dysfunctional Associations in Psychopathology: Strengths and Limitations. Journal of Behavior Therapy and Experimental Psychiatry, 33, 115-133.

https://doi.org/10.1016/S0005-7916(02)00024-1 